\title{
Clinical Outcomes and Risk Factor in Patients with STEMI Treated with Percutaneous Coronary Intervention
}

\author{
Ashraf Safiya Manzil, Venkatesh Radhakrishnan, Jithu Sam Rajan \\ Department of Cardiology, Sahakarana Hrudayalaya, Pariyaram Medical College, Kannur, India \\ Email: ashsmfz@yahoo.com
}

Received 4 October 2015; accepted 24 October 2015; published 27 October 2015

Copyright (C) 2015 by authors and Scientific Research Publishing Inc.

This work is licensed under the Creative Commons Attribution International License (CC BY). http://creativecommons.org/licenses/by/4.0/

(c) $\underset{\mathrm{EY}}{\mathrm{B}}$ Open Access

\section{Abstract}

This study was carried out to analyze risk factors and short-term clinical outcomes in different age groups of Indian patients with ST-elevation myocardial infarction who underwent percutaneous coronary intervention. This prospective, non-randomized, and observational study was carried out at a tertiary care hospital. The patients who were treated with primary percutaneous coronary intervention for ST-elevation myocardial infarction at study center from December 2011 to September 2012 were included in the study. Study population is divided into three groups: Group-I consisted of patients with age $\leq 40$ years, Group-II consisted of patients with age between $41-60$ years and Group-III consisted of patients with age $>60$ years. The primary end-point of the study was occurrence of major adverse clinical outcomes which were a composite of death, reinfarct, repeat percutaneous coronary intervention, major bleeding and emergency coronary artery bypass grafting at 30-day follow-up. A total of 200 patients with ST-elevation myocardial infarction who underwent percutaneous coronary intervention were included in the study. Among study population, $10(5 \%)$ patients constituted Group-I, 96 (48\%) patients constituted Group-II and 94 $(47 \%)$ patients constituted Group-III. Diabetes $(0 \%$ vs. $35.4 \%$ vs. $43.6 \%)$ and hypertension $(10 \%$ vs. $35.4 \%$ vs. $44.7 \%$ ) were more prevalent in Group-III as compared to Group-II and Group-I. The prevalence of single vessel disease was significantly higher in the Group-I compared to Group-II and Group-III ( $80 \%$ vs. $41.66 \%$ vs. $17 \%)$. At 30 -day clinical follow-up, the rate of occurrence of major adverse clinical outcomes in Group-I, Group-II and Group-III is $0 \%, 2 \%$ and $5.4 \%$, respectively. The young ST-elevation myocardial infarction patients had lower incidences of diabetes and hypertension compared with elderly patients. The young age group had more favorable inhospital and 30-day clinical outcomes.

\section{Keywords}

ST-Elevation Myocardial Infarction, Risk Factor, Clinical Outcomes, Epidemiological Study, 


\section{Percutaneous Coronary Intervention}

\section{Introduction}

Acute myocardial infarction (AMI) is the leading cause of death of patients hospitalized for coronary artery disease (CAD) [1] [2]. The Framigham study reported a ten-year incidence rate of myocardial infarction (MI) 12.9 in men 30 - 34 years old and 5.2 in women of 35 to 44 years old [3]. However, literature search has showed that much attention has been focused on older patients due to the fact that age is independently associated with higher mortality [4].

AMI among young patients aged 40 years or younger is rare, accounting for approximately $2 \%$ to $6 \%$ of all cases [3] [5] [6]. The lifestyles of young people, characterized by high work stress, overwork, physical inactivity, unhealthy diet, smoking and drinking alcohol likely cause coronary atherosclerosis, which increases the incidence of AMI [7]. Thus, clinical interest has been increased to study this group because of the potential of premature death and long-term disability [8]. Moreover, they are an important group to examine with regard to risk factor modification and secondary prevention.

Studies which compared risk factors, angiographic profile and clinical outcomes in young patients with STEMI from the elderly counterparts showed higher prevalence of smoking, hyperlipidemia and family history as well as lower prevalence of hypertension and diabetes in young patients with STEMI. Moreover, young patients with STEMI were more likely to have single vessel disease [3] [9]-[12]. However, these studies which analysed risk factors and compared survival among young patients with ST-elevation myocardial infarction (STEMI) with their older counterparts enrolled either mixed MI population or conducted in the thrombolytic era [6] [13]. As there were differences in risk factors and prognosis in different age groups, the present study was carried out to study risk factors and short-term clinical outcomes in different age groups of real-world patients with STEMI who underwent percutaneous coronary intervention (PCI).

\section{Material and Methods}

\subsection{Study Design and Patient Population}

This was a prospective, non-randomized, and observational study. We included all the patients who were treated with primary PCI for STEMI in Pariyaram Medical College from December 2011 to September 2012. Study population is divided into three groups: Group-I consisted of patients with age $\leq 40$ years, Group-II consisted of patients with age between 41 - 60 years and Group-III consisted of patients with age $>60$ years. The protocol of the study was approved by institutional ethics committee before the commencement of the study.

The patients' demographic information, cardiovascular history and risk factors such as, smoking, dyslipidemia, hypertension, diabetes mellitus, and family history were recorded. Dyslipidemia was defined based on total cholesterol, high-density lipoprotein and low-density lipoprotein level or use of lipid-lowering therapy by the patient. Hypertension was considered if systemic blood pressure was $\geq 140 / 90 \mathrm{mmHg}$ or if patient was receiving treatment for hypertension. Diabetes mellitus was defined as fasting blood sugar $\geq 120 \mathrm{mg} / \mathrm{dl}$ or the use specific treatment.

Pre-procedural ventricular functional assessment, mitral regurgitation and ventricular septal rupture were carried out in all patients by two-dimensional echocardiography. Significant coronary artery stenosis was defined as at least a $75 \%$ reduction in the internal diameter of the right, left anterior descending or left circumflex coronary arteries and their major branches, or a 50\% reduction in the internal diameter of the left main trunk. Successful reperfusion was defined as the establishment of TIMI grade-III flow in the infarct-related artery on the final coronary angiography.

Primary end-point of the study was occurrence of major adverse clinical outcomes (MACO) defined as a composite of death, reinfarct, repeat PCI, major bleeding, Emergency Coronary artery bypass grafting (CABG) at 30-day follow-up.

\subsection{Statistical Analysis}

Continuous variables were presented as mean \pm standard deviation (SD) and categorical variables as counts and 
percentages. All data were analysed using the Statistical Package for Social Sciences (SPSS; Chicago, IL, USA) program, version 13 .

\section{Results}

\subsection{Baseline Characteristics}

A total of 200 STEMI patients who underwent PCI were included in the study. The baseline clinical characteristics and risk factors in different age groups are depicted in Table 1. Among study population, 10 (5\%) patients constituted Group-I (patients aged $<40$ years), 96 (48\%) patients constituted Group-II (patients aged between 40 - 60 years) and 94 (47\%) patients constituted Group-III (patients aged $>60$ years). Diabetes ( $0 \%$ vs. 35.4\% vs. $43.6 \%)$ and hypertension ( $10 \%$ vs. $35.4 \%$ vs. $44.7 \%)$ were more prevalent in Group-III as compared to Group-II and Group-I.

\subsection{Angiographic and Interventional Therapy Data}

Angiographic findings as well as characteristics and results of coronary intervention have been shown in Table 2 and Table 3, respectively. The prevalence of single vessel disease was significantly higher in Group-I as compared to Group-II and Group-III (80\% vs. $41.66 \%$ vs. $17 \%)$. None of the patients in Group-I was treated for STEMI in the left main artery.

\subsection{In-Hospital and 30-Day Clinical Outcomes}

Table 4 shows in-hospital clinical outcomes and clinical outcomes during 30-day follow-up. During follow-up, 12 patients lost. None of the patients in Group-I experienced MACO at 30 day clinical follow-up during hospitalization. The rate of occurrence of MACO during hospitalization in Group-II and Group-III is $6.2 \%$ and $4.3 \%$, respectively. At 30-day clinical follow-up, the rate of occurrence of MACO in Group-II and Group-III is 2\% and $5.4 \%$, respectively.

Table 1. Baseline clinical characteristics and risk factors of STEMI patients in different age groups.

\begin{tabular}{lccc}
\hline & & Age group of STEMI patients & \\
Clinical characteristics & Group-I n $=10$ & Group-II n = 96 & Group-III n $=94$ \\
\cline { 2 - 3 } Age, mean \pm SD & $36.5 \pm 3.4$ & $54.3 \pm 8.2$ & $68.4 \pm 7.2$ \\
Female, n (\%) & $2(20 \%)$ & $13(13.5 \%)$ & $20(21.3 \%)$ \\
History of myocardial infarction, n (\%) & $2(20 \%)$ & $4(4.2 \%)$ & $0(0 \%)$ \\
Risk factors & & & $15(16 \%)$ \\
Dyslipidemia, n (\%) & $2(20 \%)$ & $22(22.9 \%)$ & $41(43.6 \%)$ \\
Diabetes, n (\%) & $0(0 \%)$ & $34(35.4 \%)$ & $42(44.7 \%)$ \\
Hypertension, n (\%) & $1(10 \%)$ & $34(35.4 \%)$ & $30(31.9 \%)$ \\
Smoker, n (\%) & $4(40 \%)$ & $48(50 \%)$ & $5(5.3 \%)$ \\
Previous myocardial infarction & $0(0 \%)$ & $4(4.2 \%)$ & $2(2.1 \%)$ \\
Chronic kidney disease, n (\%) & $0(0 \%)$ & $0(0 \%)$ & $2(2.1 \%)$ \\
Cerebrovascular accident, n (\%) & $0(0 \%)$ & $3(3.1 \%)$ & $1(1.1 \%)$ \\
Peripheral vascular disease, n (\%) & $1(10 \%)$ & $3(3.1 \%)$ & $16(17.0 \%)$ \\
KILLIP class 3/4, n (\%) & $1(10 \%)$ & $9(9.4 \%)$ & $3(3.1 \%)$ \\
Severe left ventricular dysfunction, n (\%) & $0(0 \%)$ & $2(2.1 \%)$ & $1(1.1 \%)$ \\
Ventricular septal rupture, n (\%) & $0(0 \%)$ & $1(1 \%)$ & \\
\hline
\end{tabular}


Table 2. Angiographic findings of STEMI patients.

\begin{tabular}{|c|c|c|c|}
\hline \multirow{2}{*}{ Angiographic findings } & \multicolumn{3}{|c|}{ Age group of STEMI patients } \\
\hline & Group-I $n=10$ & Group-II n = 96 & Group-III n = 94 \\
\hline \multicolumn{4}{|l|}{ Number of vessel disease } \\
\hline Single vessel disease, $\mathrm{n}(\%)$ & $8(80 \%)$ & $40(41.66 \%)$ & $16(17 \%)$ \\
\hline Double vessel disease, n (\%) & $2(20 \%)$ & $32(33.3 \%)$ & $52(55.3 \%)$ \\
\hline Tripe vessel disease, $\mathrm{n}(\%)$ & $0(0 \%)$ & $22(22.9 \%)$ & $23(24.5 \%)$ \\
\hline \multicolumn{4}{|l|}{ Treated coronary arteries } \\
\hline Left main, n (\%) & $0(0 \%)$ & $2(2.1 \%)$ & $3(3.2 \%)$ \\
\hline Left anterior descending, n (\%) & $4(40 \%)$ & $54(56.3 \%)$ & $47(50 \%)$ \\
\hline Right coronary artery, n (\%) & $4(40 \%)$ & $28(29.2 \%)$ & $26(27.7 \%)$ \\
\hline Left circumflex, n (\%) & $2(0 \%)$ & $12(12.5 \%)$ & $18(19.1 \%)$ \\
\hline
\end{tabular}

Table 3. Characteristics and results of coronary intervention of STEMI patients.

\begin{tabular}{|c|c|c|c|}
\hline & \multicolumn{3}{|c|}{ Age group of STEMI patients } \\
\hline & Group-I n = 10 & Group-II n = 96 & Group-III n = 94 \\
\hline Thrombus aspiration, $\mathrm{n}(\%)$ & $10(100 \%)$ & $94(97.9 \%)$ & $88(93.6 \%)$ \\
\hline Use of IABP, n (\%) & 0 & $2(2.1 \%)$ & $1(1.1 \%)$ \\
\hline Pre-procedural TIMI flow, no perfusion, n (\%) & $10(100 \%)$ & $96(100 \%)$ & $93(98.9 \%)$ \\
\hline Post-procedural TIMI flow, complete perfusion, n (\%) & $10(100 \%)$ & $90(93.8 \%)$ & $82(87.2 \%)$ \\
\hline \multicolumn{4}{|l|}{ Complications during procedure } \\
\hline Accelerated idioventricular rhythm, n (\%) & $0(0 \%)$ & $1(1 \%)$ & $1(1.1 \%)$ \\
\hline Atrial fibrillation, n (\%) & $0(0 \%)$ & $2(2.1 \%)$ & $2(2.1 \%)$ \\
\hline Ventricular tachycardia, n (\%) & $0(0 \%)$ & $4(4.2 \%)$ & $2(2.1 \%)$ \\
\hline Ventricular fibrillation, n (\%) & $0(0 \%)$ & $1(1 \%)$ & $4(4.3 \%)$ \\
\hline Complete heart block, n (\%) & $1(10 \%)$ & $3(3.1 \%)$ & $2(2.1 \%)$ \\
\hline Cardiac arrest, n (\%) & $0(0 \%)$ & $2(2.1 \%)$ & $2(2.1 \%)$ \\
\hline
\end{tabular}

\section{Discussion}

We carried out this study to analyse prevalence of conventional risk factors in different age groups of patients with STEMI who underwent PCI. In our study, there were 10 (5\%) STEMI patients whose age was <40 years. The results of our study showed higher prevalence of diabetes (43.6\% vs. $35.4 \%$ vs. $0 \%$ ) and hypertension (44.7\% vs. $35.4 \%$ vs. $10 \%$ ) in older patients as compared to young patients. In addition, younger patients were more likely to have single vessel disease as compared to older patients. Thus, the results of our study are consistent with the results of previous studies [3] [9]-[12]. However, these studies enrolled mixed MI population.

Literature search revealed few studies which compared risk factors, angiographic profile and clinical outcomes in young patients with STEMI from the elderly counterparts. Differences in risk profile, clinical findings and severity of coronary disease in the young from the elderly counterparts are noted in these studies [7] [14]-[17]. Hosseini et al. evaluated clinical findings and in-hospital outcomes in 2028 patients with an acute STEMI of Cardiovascular Tehran Heart Center Registry (CVDTHCR) [15]. They found higher prevalence of smoking and family history of cardiovascular disease in young patients (109 patients aged < 40 years) as compared to old patients (1919 patients aged $>40$ years). Similar findings were also found in young STEMI patients 
Table 4. Clinical outcomes after successful triple-vessel angioplasty.

\begin{tabular}{|c|c|c|c|}
\hline \multirow{2}{*}{ Clinical outcomes } & \multicolumn{3}{|c|}{ Age group of STEMI patients } \\
\hline & Group-I n = 10 & Group-II n = 96 & Group-III n = 94 \\
\hline \multicolumn{4}{|l|}{ In-hospital outcomes } \\
\hline Death, n (\%) & $0(0 \%)$ & $2(2.1 \%)$ & $3(3.2 \%)$ \\
\hline Repeat PCI, n (\%) & $0(0 \%)$ & $1(1 \%)$ & $1(1.1 \%)$ \\
\hline Major bleeding, n (\%) & $0(0 \%)$ & $2(2.1 \%)$ & $0(0 \%)$ \\
\hline Emergency CABG, n (\%) & $0(0 \%)$ & $1(1 \%)$ & $0(0 \%)$ \\
\hline Major adverse clinical outcomes, n (\%) & $0(0 \%)$ & $6(6.3 \%)$ & $4(4.3 \%)$ \\
\hline \multicolumn{4}{|l|}{ Outcomes at 30-day follow-up } \\
\hline Death, n (\%) & $0(0 \%)$ & $1(1 \%)$ & $1(1.1 \%)$ \\
\hline Repeat PCI, n (\%) & $0(0 \%)$ & $1(1 \%)$ & $2(2.1 \%)$ \\
\hline Major bleeding, n (\%) & $0(0 \%)$ & $0(0 \%)$ & $1(1.1 \%)$ \\
\hline Emergency CABG, n (\%) & $0(0 \%)$ & $0(0 \%)$ & $1(1.1 \%)$ \\
\hline Major adverse clinical outcomes, n (\%) & $0(0 \%)$ & $2(2.1 \%)$ & $5(5.3 \%)$ \\
\hline
\end{tabular}

aged less than 35 years in the study carried out by Colkesen et al. [14]. However, low prevalence of diabetes, hypertension and dyslipidemia in young patients was reported by Hosseini et al. Similarly, Waziri et al. compared risk factors and short-term clinical outcomes in 1026 young ( $<45$ years) patients and 15,659 old ( $>45$ years) patients with STEMI who underwent primary PCI [18]. They found higher prevalence of smokers $(71.2 \%$ vs. $44.2 \%, \mathrm{p}<0.001)$ and lower prevalence of hypertension $(17.3 \%$ vs. $39.3 \%, \mathrm{p}<0.001)$, hyperlipidemia $(18.0 \%$ vs. $23.8 \%, \mathrm{p}<0.001)$, diabetes (9.0\% vs. $12.4 \%, \mathrm{p}<0.001)$ and previous myocardial infarction $(6.9 \%$ vs. $12.2 \%$, $\mathrm{p}<0.001$ ) in young patients with STEMI compared with older patients. Yunyun et al. concluded that fibrinogen and glycosylated haemoglobin are associated with young STEMI patients (individuals $\leq 44$ years of age) apart from conventional risk factors (male sex, smoking and family history of early CAD) [7].

Several studies also compared clinical outcomes in younger patients and old patients with STEMI. In our study, MACO were lower in young patients as compared to old patients. Lee et al. also found favorable inhospital outcomes (cardiac death, MI, repeated PCI or CABG) in younger Korean patients with STEMI [16]. However, after adjustment for the potential confounders, the clinical outcomes of patients in the young age group were not found superior by the authors to those of patients in the old age group at the one-year follow-up.

The major limitation of this study was smaller sample size. Statistical significance was not comparable with many studies as we had sample size of only 200 compared to many randomized. However, our study highlights difference in the prevalence of risk factor in different age groups.

\section{Conclusion}

The young STEMI patients had lower incidences of diabetes and hypertension compared with elderly patients. The young age group had more favorable in-hospital and 30-day clinical outcomes.

\section{References}

[1] Murray, C.J.L. and Lopez, A.D. (1997) Global Mortality, Disability, and the Contribution of Risk Factors: Global Burden of Disease Study. The Lancet, 349, 1436-1442. http://dx.doi.org/10.1016/S0140-6736(96)07495-8

[2] Murray, C.J.L. and Lopez, A.D. (1997) Mortality by Cause for Eight Regions of the World: Global Burden of Disease Study. The Lancet, 349, 1269-1276. http://dx.doi.org/10.1016/S0140-6736(96)07493-4

[3] Zimmerman, F.H., Cameron, A., Fisher, L.D. and Ng, G. (1995) Myocardial Infarction in Young Adults: Angiographic Characterization, Risk Factors and Prognosis (Coronary Artery Surgery Study Registry). Journal of the American College of Cardiology, 26, 654-661. http://dx.doi.org/10.1016/0735-1097(95)00254-2 
[4] De Luca, G., Dirksen, M.T., Spaulding, C., Kelbæk, H., Schalij, M., Thuesen, L., et al. (2015) Impact of Age on Long-Term Outcome after Primary Angioplasty with Bare-Metal or Drug-Eluting Stent (from the DESERT Cooperation). American Journal of Cardiology, 112, 181-186. http://dx.doi.org/10.1016/j.amjcard.2013.03.012

[5] Imazio, M., Bobbio, M., Bergerone, S., Barlera, S. and Maggioni, A.P. (1998) Clinical and Epidemiological Characteristics of Juvenile Myocardial Infarction in Italy: The GISSI Experience. Giornale Italiano di Cardiologia, 28, 505512.

[6] Chua, S.K., Hung, H.F., Shyu, K.G., Cheng, J.J., Chiu, C.Z., Chang, C.M., et al. (2010) Acute ST-Elevation Myocardial Infarction in Young Patients: 15 Years of Experience in a Single Center. Clinical Cardiology, 33, 140-148. http://dx.doi.org/10.1002/clc.20718

[7] Wang, Y.Y., Li, T., Liu, Y.W., Liu, B.J., Wang, Y., Hu, X.M., et al. (2014) Analysis of Risk Factors of ST-Segment Elevation Myocardial Infarction in Young Patients. BMC Cardiovascular Disorders, 14, 179. http://dx.doi.org/10.1186/1471-2261-14-179

[8] Weinberger, I., Rotenberg, Z., Fuchs, J., Sagy, A., Friedmann, J. and Agmon, J. (1987) Myocardial Infarction in Young Adults under 30 Years: Risk Factors and Clinical Course. Clinical Cardiology, 10, 9-15. http://dx.doi.org/10.1002/clc.4960100104

[9] Shiraishi, J., Kohno, Y., Yamaguchi, S., Arihara, M., Hadase, M., Hyogo, M., et al. (2005) Acute Myocardial Infarction in Young Japanese Adults. Circulation Journal, 69, 1454-1458. http://dx.doi.org/10.1253/circj.69.1454

[10] Shiraishi, J., Kohno, Y., Yamaguchi, S., Arihara, M., Hadase, M., Hyogo, M., et al. (2006) Medium-Term Prognosis of Young Japanese Adults Having Acute Myocardial Infarction. Circulation Journal, 70, 518-524. http://dx.doi.org/10.1253/circj.70.518

[11] Chen, Y.-L., Bhasin, A., Youssef, A.A., Wu, C.-J., Yang, C.-H., Hsieh, Y.-K., et al. (2009) Prognostic Factors and Outcomes in Young Chinese Patients with Acute Myocardial Infarction Undergoing Primary Coronary Angioplasty. International Heart Journal, 50, 1-11. http://dx.doi.org/10.1536/ihj.50.1

[12] Kanitz, M.G., Giovannucci, S.J., Jones, J.S. and Mott, M. (1996) Myocardial Infarction in Young Adults: Risk Factors and Clinical Features. The Journal of Emergency Medicine, 14, 139-145. http://dx.doi.org/10.1016/0736-4679(95)02089-6

[13] Puricel, S., Lehner, C., Oberhänsli, M., Rutz, T., Togni, M., Stadelmann, M., et al. (2013) Acute Coronary Syndrome in Patients Younger than 30 Years-Aetiologies, Baseline Characteristics and Long-Term Clinical Outcome. Swiss Medical Weekly, 143, w13816. http://dx.doi.org/10.4414/smw.2013.13816

[14] Colkesen, A.Y., Acil, T., Demircan, S., Sezgin, A.T. and Muderrisoglu, H. (2008) Coronary Lesion Type, Location, and Characteristics of Acute ST Elevation Myocardial Infarction in Young Adults under 35 Years of Age. Coronary Artery Disease, 19, 345-347. http://dx.doi.org/10.1097/MCA.0b013e3283030b3b

[15] Hosseini, S.K., Soleimani, A., Karimi, A.A., Sadeghian, S., Darabian, S., Abbasi, S.H., et al. (2009) Clinical Features, Management and In-Hospital Outcome of ST Elevation Myocardial Infarction (STEMI) in Young Adults under 40 Years of Age. Monaldi Archives for Chest Disease, 72, 71-76.

[16] Lee, S.H., Kim, J.H., Jeong, M.H., Park, H., Jeong, Y.A., Ahn, Y., et al. (2015) Clinical Characteristics and Outcomes of Acute ST-Segment Elevation Myocardial Infarction in Younger Korean Adults. Korean Circulation Journal, 45, 275-284. http://dx.doi.org/10.4070/kcj.2015.45.4.275

[17] Karim, M.A., Majumder, A.A.S., Islam, K.Q., Alam, M.B., Paul, M.L., Islam, M.S., et al. (2015) Risk Factors and In-Hospital Outcome of Acute ST Segment Elevation Myocardial Infarction in Young Bangladeshi Adults. BMC Cardiovascular Disorders, 15, 73. http://dx.doi.org/10.1186/s12872-015-0069-2

[18] Waziri, H., Jørgensen, E., Kelbæk, H., Stagmo, M., Pedersen, F., Lagerqvist, B., et al. (2015) Short and Long-Term Survival after Primary Percutaneous Coronary Intervention in Young Patients with ST-Elevation Myocardial Infarction. International Journal of Cardiology. http://dx.doi.org/10.1016/j.ijcard.2015.09.012 